\title{
Editorial
}

Dermatology

\section{Measles: An Ongoing Story}

\author{
Franck Boralevi \\ Unité de Dermatologie Pédiatrique, Hôpital Pellegrin-Enfants, Bordeaux, France
}

Measles appears today as a re-emerging infectious disease in Europe, mainly due to the suboptimum vaccination coverage in some European countries. Although cases of measles became rare in early 2000, an underestimated number of 7,822 cases have been recorded in Europe in 2008, and a higher number of cases is expected this year [1]. Six countries are particularly affected, namely Switzerland, Italy, the UK, Germany, France and Austria. Most cases occurred in unvaccinated or incompletely vaccinated children. With 27.45 cases per 100,000 inhabitants, Switzerland shows the highest incidence rate in Europe [1]. In France, the quite low measles incidence rate of 1 case per 100,000 measured in 2008 hides a tenfold increase compared to 2006-2007. Thus, the expected elimination of the virus by 2010 will not be reached. Nevertheless, measles elimination remains a goal that should be attained by the achievement of optimum vaccination coverage and by improvement in our ability to recognize measles earlier in order to limit the risks of local outbreaks. Koplik's sign, nicely illustrated in the report by Lefebvre et al. in this issue [2], remains a simple and helpful feature that permits the early detection of measles.

For decades, Koplik's sign has belonged to the universal medical knowledge and is considered as a pathognomonic feature of measles. Such pathognomonic signs are rare in medical practice; however, it appears that careful examination of the mouth to find Koplik's sign is not systematically performed in patients seen with a febrile rash. There are several reasons for this. Firstly, searching for Koplik's sign requires a careful examination of the entire buccal mucous membrane that is not easy to perform in young children. Secondly, Koplik's sign may appear as an unclear old description of white or gray or bluish mucosal specks very exceptionally illustrated in dermatology or infectious disease textbooks. Thirdly, measles has become a rare condition in the European countries during the past decades so that the opportunity for physicians to meet patients with Koplik's sign appears improbable.

Henry Koplik was an influential American pediatrician at the end of the 19th century. He contributed to the universal medical knowledge by describing the buccal mucous membrane signs observed in early measles, before the skin rash occurs [3]. Indeed, his contribution was to describe precisely the mucous involvement in measles - signs that had been previously mentioned by anonymous French authors - and to show the pathognomonic nature of these features. About 100 years after his paper was published, Koplik's sign remains a remarkable way to recognize measles at an early stage, for example in patients with febrile cough or coryza, even before the skin rash appears.

\section{References}

1 Muscat M, Bang H, Glismann S, Mølbak K: An epidemiological assessment of measles in Europe, 2008. Bull Epidemiol Hebd 2009;39-40: 436-440.

2 Lefebvre N, Camuset G, Bui E, Christmann D, Hansmann Y: Koplik spots: a clinical sign with epidemiological implications for measles control. Dermatology DOI: 10.1159/000277122.

3 Koplik H: The diagnosis of the invasion of measles from a study of the exanthema as it appears on the buccal mucous membrane. Arch Paediatr 1896;13:918-922.

\section{KARGER}

Fax +4161306 1234

E-Mail karger@karger.ch

www.karger.com
C) 2010 S. Karger AG, Basel

$1018-8665 / 10 / 2203-0193 \$ 26.00 / 0$

Accessible online at:

www.karger.com/drm
Prof. Franck Boralevi

Unité de Dermatologie Pédiatrique, Hôpital Pellegrin-Enfants

Place Amélie Raba-Léon

FR-33076 Bordeaux Cedex (France)

Tel. +33 556795 622, Fax +33 556795 987, E-Mail franck.boralevi@chu-bordeaux.fr 